\title{
Stool banking for fecal microbiota transplantation: ready for prime time?
}

\author{
Srishti Saha, Sahil Khanna \\ Division of Gastroenterology and Hepatology, Mayo Clinic, Rochester, MN, USA \\ Correspondence to: Sahil Khanna, MBBS, MS. Division of Gastroenterology and Hepatology, Mayo Clinic, 200 First St SW, Rochester, MN 55905, \\ USA. Email: khanna.sahil@mayo.edu. \\ Comment on: Cammarota G, Ianiro G, Kelly CR, et al. International consensus conference on stool banking for faecal microbiota transplantation in \\ clinical practice. Gut 2019;68:2111-21.
}

Submitted Mar 14, 2020. Accepted for publication Apr 01, 2020.

doi: 10.21037/hbsn-20-371

View this article at: http://dx.doi.org/10.21037/hbsn-20-371

Fecal microbiota transplantation (FMT) has emerged as an effective treatment for recurrent Clostridioides difficile infection (CDI) and is recommended as a standard of care (1). Since the first randomized clinical trial published in 2013, there has been an exponential rise in the number of FMTs being performed (2). However, access to FMT varies according to location and type of healthcare establishment and is complicated by the regulatory issues surrounding its use $(3,4)$. Storing and banking stool may be an accessible and economical option for patients requiring FMT, considering the costs associated with donor screening, stool processing and storage by individual providers (5).

An international consensus conference was held on stool banking for FMT, which provides a comprehensive guidance document for institutions interested in setting up a stool bank (6). The guideline provides 40 statements, 17 of which were developed in accordance with the GRADE approach and 23 were based on expert opinion.

The ability to freeze, preserve and bank donor stool has improved access to FMT. Stool banks aim to safely collect, store, and distribute stool product for treatment of CDI, and may participate in research studies under strict protocols. It is being suggested that if stool banks are established, it must be done in accordance with federal regulatory guidelines for FMT, and the director of the stool bank along with a scientific committee must ensure adherence to such guidance.

Stool donation is voluntary and should be done under informed consent. Potential donors are mandated to undergo screening via a health interview, along with blood and stool testing. Comprehensive screening protocols are required to prevent the occurrence of infectious and noninfectious conditions potentially transmissible through transfer of the gut microbial community. The guideline provides a number of questions and tests to be included as a standard of procedure for screening donors (6). However, this is not an exhaustive list and screening should be modified as per local disease patterns and individual susceptibilities (e.g., screening and counselling of immunocompromised patients for CMV, testing for common parasitic pathogens in appropriate geographical regions).

Despite presence of such guidance, serious infectious complications have been reported $(7,8)$. In addition to the tests being defined, it is imperative to define the testing modality used for individual tests (for instance enzyme immunoassay versus polymerase chain reaction), so that tests with highest sensitivity are used, as some of the tests available are validated to diagnose disease and not screen asymptomatic individuals. Testing for infectious agents should be validated in healthy adults. In addition to providing tests used by stool banks, the sensitivity and specificity of tests used should be disclosed to patients receiving these therapies.

Donor re-screening should be done at pre-defined intervals (every 8-12 weeks) and it is recommended that stool product must be embargoed till such time. It is important to note that depending on the population solicited to be a donor, a significant proportion of potential 
donors (60-90\%) may fail screening, most of them during the health interview and physical examination $(50-75 \%$ of potential donors screened out) (5,9-11). It may be imperative to establish workflows to maintain a steady pool of donors within the unique limitations of the local population.

Donors must be provided clear instructions for stool collection. Each stool sample should be uniquely labelled for batch traceability, allowing thorough investigation in case of adverse events (AEs). Stool banks should have biosafety level 2 facilities to allow for processing and storage of stool. Stool must be transported within 6 hours, processed, and stored at $-80{ }^{\circ} \mathrm{C}$. Stored samples should be used within 2 years of donation, preferably within 1 year. Storage at the site of FMT administration should ideally be done at $-80{ }^{\circ} \mathrm{C}$ but product may be stored at $-20{ }^{\circ} \mathrm{C}$ for up to 30 days if $-80{ }^{\circ} \mathrm{C}$ freezers are not available. Product should be thawed to room temperature at the time of FMT. FMT should be performed under the supervision of a trained physician, and access to stool product should not be provided directly to patients. In order to maintain traceability of donor product, an aliquot from each stool donation should be preserved and medical records of donors should be adequately maintained in registries. Severe AEs after FMT must be closely monitored and reported to institutional and regulatory authorities; potentially related minor AEs must also be recorded.

At present, in clinical settings FMT may be performed for patients with recurrent CDI (3 or more episodes); patients with severe or fulminant CDI with no response to antibiotic therapy may be offered FMT, particularly when surgery is not feasible. Use of FMT in other conditions such as inflammatory bowel disease, irritable bowel syndrome, metabolic diseases and others, is currently under investigation. Pending the availability of high-quality evidence, FMT should not be routinely offered to these patients. For non-CDI indications, clinical trials provide the best option for interested patients; use of FMT can be considered for compassionate use in very specific situations, with appropriate informed consent and with approval from local ethics committees.

Stool banking can be local for use at an individual institution, though some centrally operated stool banks are in existence. Stool banking provides the option of a centralized, accessible, convenient and economically feasible FMT product. However, banked stool material should be studied for efficacy and safety prior to commercial use. Research surrounding the use and safety of FMT in CDI and other diseases is evolving rapidly. The guideline presented here is a valuable starting point for establishing stool banks. However, it should be noted that evidence regarding several aspects of FMT is still limited, which is reflected in the fact that only 7 of the 17 recommendations had a moderate or high certainty of evidence.

The United States Food and Drug Administration (FDA) has issued a draft guidance (not enforced) for FMT and suggests that stool should not be obtained from a central stool bank (12). The FDA suggests that stool donors should be known to the patient or the provider. With more clarity from the FDA and other regulatory authorities, and research into the most effective and safe stool products, the current landscape of stool banking may change. In addition, established safety, efficacy, oversight and regulation are needed to see if there would be a role for centralized and regulated stool banks. Standardized and rigorously implemented procedures for donor screening, stool donation, processing and storage, rigorous efficacy and safety data with clinical trials rather than case series, and traceability of stool product would be needed for such facilities to exist.

In addition to development of stool banks, standardized microbiome-based therapeutics are being developed and phase III clinical trials are being completed (clinicaltrials. gov identifier: NCT03183128, NCT03244644). The future would herald the availability of standardized therapies in capsule and enema-based forms. Expanding interest in the development of tailored products would likely lead to the development of enriched stool products, with selection of specific components of the stool known to be most efficacious. Development of microbial consortia and 'microbial banking' as opposed to stool banking may be a further step forward. Use of FMT beyond CDI may change donor screening and selection criteria, with stool product from specific donors or 'super donors' administered for specific diseases (13). Akin to stem cell and sperm banks, patients may in the future opt for storage of their stool for use as autologous FMT when needed.

To conclude, stool banking may be an accessible way for collection and distribution of stool product for FMT with several caveats. The current guideline should be used as a starting point for establishing stool banks, with close attention to newer evidence regarding FMT. Additional guidance from the FDA and other regulatory authorities is awaited.

\section{Acknowledgments}

Funding: None. 


\section{Footnote}

Provenance and Peer Review: This article was commissioned by the editorial office, Hepatobiliary Surgery and Nutrition. The article did not undergo external peer review.

Conflicts of Interest: Both authors have completed the ICMJE uniform disclosure form (available at https://hbsn. amegroups.com/article/view/10.21037/hbsn-20-371/coif). SK reports other from Rebiotix, A Ferring Company, outside the submitted work; and Consulting fees from Shire Plc, Premier, Inc., Facile therapeutics, ProbioTech, Inc., outside of the submitted work. The other author has no conflicts of interest to declare.

Ethical Statement: The authors are accountable for all aspects of the work in ensuring that questions related to the accuracy or integrity of any part of the work are appropriately investigated and resolved.

Open Access Statement: This is an Open Access article distributed in accordance with the Creative Commons Attribution-NonCommercial-NoDerivs 4.0 International License (CC BY-NC-ND 4.0), which permits the noncommercial replication and distribution of the article with the strict proviso that no changes or edits are made and the original work is properly cited (including links to both the formal publication through the relevant DOI and the license). See: https://creativecommons.org/licenses/by-nc-nd/4.0/.

\section{References}

1. McDonald LC, Gerding DN, Johnson S, et al. Clinical Practice Guidelines for Clostridium difficile Infection in Adults and Children: 2017 Update by the Infectious Diseases Society of America (IDSA) and Society for Healthcare Epidemiology of America (SHEA). Clin Infect Dis 2018;66:987-94.

2. van Nood E, Vrieze A, Nieuwdorp M, et al. Duodenal infusion of donor feces for recurrent Clostridium difficile. N Engl J Med 2013;368:407-15.

3. Joseph J, Saha S, Greenberg-Worisek AJ. Fecal Microbiota Transplantation: An Ambiguous Translational Pathway for a Promising Treatment. Clin Transl Sci 2019;12:206-8.

Cite this article as: Saha S, Khanna S. Stool banking for fecal microbiota transplantation: ready for prime time? HepatoBiliary Surg Nutr 2021;10(1):110-112. doi: 10.21037/hbsn-20-371
4. Quraishi MN, Segal J, Mullish B, et al. National survey of practice of faecal microbiota transplantation for Clostridium difficile infection in the UK. J Hosp Infect 2017;95:444-5.

5. Craven LJ, Nair Parvathy S, Tat-Ko J, et al. Extended Screening Costs Associated With Selecting Donors for Fecal Microbiota Transplantation for Treatment of Metabolic Syndrome-Associated Diseases. Open Forum Infect Dis 2017;4:ofx243.

6. Cammarota G, Ianiro G, Kelly CR, et al. International consensus conference on stool banking for faecal microbiota transplantation in clinical practice. Gut 2019;68:2111-21.

7. DeFilipp Z, Bloom PP, Torres Soto M, et al. DrugResistant E. coli Bacteremia Transmitted by Fecal Microbiota Transplant. N Engl J Med 2019;381:2043-50.

8. FDA. Fecal Microbiota for Transplantation: Safety Alert - Risk of Serious Adverse Events Likely Due to Transmission of Pathogenic Organisms. Available online: https://www.fda.gov/safety/medical-product-safetyinformation/fecal-microbiota-transplantation-safety-alertrisk-serious-adverse-events-likely-due-transmission

9. Tariq R, Weatherly R, Kammer P, et al. Donor Screening Experience for Fecal Microbiota Transplantation in Patients With Recurrent C. difficile Infection. J Clin Gastroenterol 2018;52:146-50.

10. Paramsothy S, Borody TJ, Lin E, et al. Donor Recruitment for Fecal Microbiota Transplantation. Inflamm Bowel Dis 2015;21:1600-6.

11. Costello SP, Tucker EC, La Brooy J, et al. Establishing a Fecal Microbiota Transplant Service for the Treatment of Clostridium difficile Infection. Clin Infect Dis 2016;62:908-14.

12. FDA. Enforcement Policy Regarding Investigational New Drug Requirements for Use of Fecal Microbiota for Transplantation to Treat Clostridium difficile Infection Not Responsive to Standard Therapies. Available online: https:// www.fda.gov/regulatory-information/search-fda-guidancedocuments/enforcement-policy-regarding-investigationalnew-drug-requirements-use-fecal-microbiota-0

13. Wilson BC, Vatanen T, Cutfield WS, et al. The SuperDonor Phenomenon in Fecal Microbiota Transplantation. Front Cell Infect Microbiol 2019;9:2. 